\title{
Rationality and the refusal of medical treatment: a critique of the recent approach of the English courts
}

\author{
Marc Stauch Nottingham Law School
}

\begin{abstract}
This paper criticises the current approach of the courts to the problem of patients who refuse life-saving medical treatment. Recent judicial decisions have indicated that, so long as the patient satisfies the minimal test for capacity outlined in Gillick, the courts will not be concerned with the substantive grounds for the refusal. In particular, a 'rationality requirement' will not be imposed. This paper argues that, whilst this approach may accord with our desire to uphold the autonomy of a patient who refuses treatment on religious grounds, it fails to address the problem of the deluded

decision-maker whose refusal is based on wrongheaded reasons (and where talk of autonomy is a disservice).

The difficulty can be overcome, however, by recognising that the two patients in fact inhabit distinct realms - the non-rational and the irrational. The test for capacity, at least in the context of life-saving treatment, should revert accordingly to the older concept of 'sound mind', to disallow refusals of an irrational (as opposed to a non-rational) nature.
\end{abstract}

The prevailing view of the courts in this country as to when a patient has the right to refuse medical treatment is apparent from a number of recent decisions, and found forceful expression in $R e T$ (1992) (1), a case revolving around the apparent refusal of a former Jehovah's Witness to submit to a life-saving blood transfusion. According to Lord Donaldson MR: 'An adult patient who ... suffers from no mental incapacity has an absolute right to choose whether to consent to medical treatment .... This right of choice is not limited to decisions which others might regard as sensible. It exists notwithstanding that the reasons for making the choice are rational, irrational, unknown or even nonexistent' (2).

The first part of the above dictum seems initially simply to echo the well-known principle, first asserted by Cardozo J, to the effect that 'every human being of adult years and sound mind has a right to determine what shall be done with his own

\section{Key words}

Right to refuse treatment; capacity; rationality; autonomy. body' (3). However, in speaking not as Cardozo did of 'sound mind', but rather in terms of 'lack of mental incapacity', Lord Donaldson is making an appeal to the modern concept of 'capacity', whicl dates from the House of Lords' judgment in Gillick oo West Norfolk and Wisbech $A H A$ (4). It was held in? that case that, for a patient to have capacity, and thus to be able to consent to treatment, it is sufficient that he or she can foresee and appreciate the nature and consequences of the treatment decision that he्छ or she is making. It then naturally follows, as Lord Donaldson goes on to assert in the second part of hip dictum, that the actual choice made, including the grounds for it (in so far as there are any), are matter for the patient alone. By contrast, the older and les: sharply defined test of 'soundness of mind' would, i 2 seems certain, have included within its remit some scrutiny of the grounds for the patient's decision.

This paper will focus upon the effect of this news approach - I will refer to it as the ' $R e T$ approach' ( 5 p - in the context of life-saving treatment. The issue is. given piquancy by the recent High Court decision in $\operatorname{Re} C$ (1993) (6) in which Thorpe J, following $\operatorname{Re} T$; upheld the refusal of a mentally ill patient to submit. to a life-saving amputation of a gangrenous foot.

At first sight, the $\operatorname{Re} T$ approach may appear to accord commendably with our desire to protect the patient as far as we are able against the paternalis $\square$ interference of others. By separating the capacity to․ make a treatment decision from the rationality on otherwise of that decision, we appear to give proper weight to the autonomy of the individual. The alternative, allowing choice but then discounting those choices adjudged to be irrational, seems equivalent to giving the patient no real choice at alko Indeed, doing this would, it seems, simply be a case of preferring a beneficence-based approach, which ${ }^{+}$ stresses the patient's best interests, to one in which his autonomy is paramount.

The $R e T$ approach has also been endorsed by the Law Commission in respect of mentally disordered patients. In its consultation paper no 129 (Mentall Incapacitated Adults and Decision-making) th 8 commission proposes that for a patient to make at effective decision whether or not to receive medica) treatment, it should normally suffice that: 'he or she्? 
is [able] to understand an explanation ... of the basic information relevant to taking it, including information about the reasonably foreseeable consequences of taking or failing to take it, [and] is [able] to retain the information for long enough to take an effective decision' (7).

A 'rationality test', ie, the requirement that the choice should be a rational one, is expressly rejected (8).

For all its apparent plausibility, however, at least in the context of life-saving treatment, the $R e T$ approach does give rise to a number of difficulties, which have not, as yet, been adequately addressed. We may begin by recognising the tension which invariably exists whenever a patient is allowed to refuse this form of treatment. This is because the principle of patient autonomy, to which we are granting primacy, is in conflict with at least one (and normally two) other principle(s). The first of these is the doctrine of the sanctity of human life, which, as the courts have recognised (9), society has an interest in upholding. Secondly, there are the best interests of the patient himself, which, save in the most extreme instance of an existence which is 'demonstrably awful', are presumed to operate in favour of prolonging life (10).

Consider the following possible examples of patients, all - let us assume - with capacity as defined in Gillick, who indicate such a refusal:

1) a patient who will in the event of the treatment survive only in great pain and without many of his mental or physical faculties;

2) a Jehovah's Witness who believes that the form of treatment required (a blood transfusion) will bar his eternal salvation;

3) a patient who is under the delusion that she is or will be a great actress and the treatment would have the effect of preventing this.

How are these examples relevant? Firstly, they may contribute to our sense of unease in relation to the $\operatorname{Re} T$ approach. We feel intuitively that there are important differences between the three cases, such that the first and second patients' grounds for refusing the treatment deserve to be taken far more seriously than those of the third. Can an approach which refuses even to consider these grounds really be correct? On the other hand, however, the facts of the second case seem to justify the current reluctance to make the patient's choice subject to a 'rationality test'. The Jehovah's Witness's decision to refuse the treatment should, many of us would feel, be respected, even if we believe that it lacks rationality.

The basis of these contrary intuitions lies in the assumption that the patient's grounds for his decision, in so far as they are not rational, must by definition be irrational (11). In order, then, not to risk impugning the respectable type of 'irrationality'
- that of the Jehovah's Witness - we think it better to avoid delving into the grounds of the patient's decision altogether. However, the assumption is wrong; a ground which is not rational does not have to be irrational - it can instead be non-rational. It is in fact worth enlarging upon these distinct categories of grounds a patient may have for refusing treatment, as follows:

\section{1: Rational grounds}

These grounds can be characterised as being founded upon 'commonsense'. They disclose a set of beliefs which are derived from concepts given to us in our normal everyday experience of the world (including that of our own bodies). For example, we experience pleasure as a good, and pain as a bad, and are aware that some states of affairs in the world are conducive to the former, and others to the latter. It is natural to desire those states where pleasure holds sway over pain, and, where there is a choice, it will be rational to choose accordingly. In the case of a choice which results in death, such as a decision by a patient to refuse life-saving treatment, a difficulty arises in that the nature of the life foregone cannot be compared with a state which remains unknown. Nevertheless, in certain, perhaps rare, circumstances, we may be justified in regarding such a choice as rational. This would be the type of case where the quality of the life to be renounced is so certain to be intolerable that, were the patient incompetent and the court being asked to make the decision, it would hold that the treatment should be withheld in the patient's best interests.

\section{2: Non-rational grounds}

These are founded upon ideas that are not given to us in our normal experience of the world. Such 'nonempirical ideas' are typically found within systems of religious faith, where reference is made to 'truths' which lie 'beyond' our experience of the world. Indeed, within monotheistic religions, the most fundamental of such ideas is that of a God or divine presence. Because such ideas do not derive from claims about the world of objective experience, any beliefs founded upon them must be a matter of faith rather than reason. However, whilst the effect of this is that such beliefs are empirically unverifiable, it means that they are not demonstrably false either.

\section{3: Irrational grounds}

Here the discussion will focus upon cases of what may be termed 'cognitive irrationality'. That is where the decision involves a belief of some form, but one based upon concepts that 'fly in the face' of our normal experience of the world. Just as in the case of rational grounds, then (and in contrast to non-rational grounds), claims are being made about 
the world of experience. Here, though, the claims are false.

If we now return to the three examples of patients refusing life-saving treatment, it is evident that 1 ) has chosen rationally, 2) has chosen non-rationally, and 3) has chosen irrationally. As already discussed, upholding a decision by a patient to forego lifesaving treatment gives rise to a tension because the principle of patient autonomy has been allowed to prevail over the doctrine of the sanctity of human life and (in most cases) the patient's own best interests. However, as will be seen, the degree of this tension differs markedly according to the nature of the patient's choice.

\section{Automatic accord}

Firstly, in the case of the rational decision, the tension is minimal. There is an automatic accord between the patient's autonomy and his best interests and, whilst the decision does go against the sanctity of human life, the latter is not an absolute principle. As is clear from those cases in which the courts have been required to rule upon life-saving treatment involving incompetent patients, it must yield ultimately to the patient's best interests (12).

Turning next to the person who refuses life-saving treatment on non-rational grounds, this case, too, causes relatively little difficulty; we intuitively feel that, with regard to the Jehovah's Witness, the principle of autonomy should prevail. Why exactly is this? Part of the reason seems to be that, in terms of content, religious beliefs and values are, as $M$ Wreen has argued, 'not on a par with other beliefs and values that a [purely] rational person might have'. In its attempt to describe and explain the human condition at its most fundamental level, religion has to do with 'securing a sense of personal identity and providing life with a meaning .... Not to respect an autonomous person's refusal of treatment when that refusal is religiously based is not to respect him as a person at the deepest level, the level at which he has tried to reconcile himself to the limitations of his own human existence ...' (13).

A second factor is, as I have argued, that religious beliefs are non-rational in basis, and therefore have the formal quality of being neither verifiable nor falsifiable. This means that it is simply not possible, where such beliefs are prudential in character (for example, the Jehovah Witness's belief that in order to be saved he must not receive blood), to assimilate them within a beneficence-based 'best interests' test. The latter, which trades upon the pleasure and pain that we derive from our experience of the world, cannot allow that which is unknowable into its equation.

The third of the cases given above, that of the irrational patient, undoubtedly presents the greatest problems. A cognitively irrational choice to refuse life-saving treatment will involve a delusion, ie, a false belief in some state of affairs, such that death $\frac{\text { T. }}{5}$ (recognised as the consequence of refusal) appears to the patient to be his most attractive option. Ian. Kennedy has suggested that, in the case of a patientos who refuses treatment while operating under a short $=0$ term delusion, the doctor would be entitled to goo ahead and treat (14). It is not clear upon what principle this assertion is based; once it might have been possible to deny that such a patient was ofo 'sound mind', but now, supposing him (as may well ${ }^{\text {( }}$ be the case) to satisfy the Gillick test for capacity, his. choice should in theory be upheld. Nevertheless $\vec{\omega}$ most people would probably agree that the doctoro ought indeed to treat.

Kennedy offered, by way of contrast, the case $e_{n}^{\Phi}$ which I used as one of the examples above, of thewould-be actress who refuses treatment as it would ${ }^{\omega}$ prevent her from achieving this aim. In fact, as Kennedy's example continues, 'she is elderly and haso been in an institution since she was a child, but she seems to sustain herself by her belief that one day shec will be a star'. In such a case as this, Kennedy believes, the doctors should regard the patient as capable of refusing the treatment. This is because 'to $\oplus$ argue otherwise would effectively be to rob the ${ }^{\text {or }}$ patient of his right to his own personality which may be far more serious and destructive than anything that could follow from the patient's decision as regards a particular proposed treatment' (14).

Now the assumption in this paper, of course, is@ that without the treatment in question the patient $\overrightarrow{\vec{F}}$ will die. Even so Kennedy's argument appears as $\overline{3}$ though it could still hold good, especially if the patient's future life - bereft of the one belief that? had made it pleasurable - is likely to be thoroughly miserable. Is this, however, a case of the autonomy of the patient being accorded priority, or are weo actually applying a 'best interests' test in disguise? Possibly, the reason for our unwillingness to tampero with the patient's refusal in this case, is the feeling that, if her continued existence will indeed be one? of unmitigated suffering, she may be 'better off dead'.

Consider a different example, that of a muchN younger mental patient, say a 25 -year-old man, who, operating under a long-term delusion that his sole purpose in life is to be a great footballer, refuses a life-saving foot-amputation. Here, our intuition maye be that the patient's irrational refusal should be overridden. Certainly, and in contrast to the case ofec the would-be actress, an application of the best ${ }^{-}$ interests test would unambiguously favour such $\mathrm{a}^{0}$ result.

It would be disturbing if such considerations? could be side-stepped by invoking, ostensibly in thee irrational patient's favour, the principle of autonomy. The latter is arguably meaningless ing such a context. It relies for too much of its appeato upon the theory that the individual is the best judge of his own good - the idea that it is through being left? 
alone, to act in accordance with a set of self-imposed ends and values, that a person achieves the greatest fulfilment. That presumption is surely rebutted in the sad case of a deluded patient whose irrational choice is going to cost him his life.

By allowing the possibility of irrational patients having capacity, the $R e T$ approach fails to recognise any such limitations upon the principle of autonomy. As I have argued, it is an approach which can be traced back to the failure to distinguish between non-rational and irrational grounds for decisions. This has meant that the problem of the deluded decision-maker has been overshadowed by the desire to accord respect to the autonomy of the religious treatment-refuser.

Let us now, in the light of the foregoing discussion, look in greater detail at the recent decisions of the High Court in the case of $\operatorname{Re} C(15)$. $C$ was a 68-year-old in-patient at Broadmoor, suffering from paranoid schizophrenia. $\mathrm{He}$ developed gangrene in a foot and his doctors were of the view that an amputation would be required to save his life. $\mathrm{C}$ refused this and indeed responded reasonably well to conventional treatment, but there remained a danger that the gangrene would return. Against this background, he applied to the court for an injunction, restraining his doctors from carrying out the amputation either now or in the future without his express written consent.

It appears that C's refusal was bound up with a mixture of non-rational and irrational reasons. In the words of Thorpe J: '[ $\mathrm{Mr} \mathrm{C}]$ expressed the grandiose delusions of an international career in medicine during the course of which he had never lost a patient. $\mathrm{He}$ affirmed his complete faith in God and, subject to one reservation, in the bible. He expressed complete confidence in his ability to survive his present trials aided by God, the good doctors and the good nurses. Although he recognised that he would die, death would not be caused by his foot. As he made clear in re-examination, that was his belief, although he could not say that that would not happen'.

Significantly Thorpe J accepted the view of two doctors that there was no direct link between C's refusal and his persecutory delusions, commenting that 'his rejection of amputation seemed to result from sincerely held convictions' (15).

On the basis of the above, the decision in $\operatorname{Re} C$ may arguably have been correct. That is if the operative grounds for C's refusal were indeed of a non-rational, religious character. Respect for C's autonomy should then be the paramount consideration. Contrast the position, however, if the main reason for the refusal was based upon C's delusion that he was a famous surgeon. In that case, giving effect to his 'autonomy' would hardly have been acceptable. Instead the relevant starting point for the court ought to have been the 'best interests' test and the principle of the sanctity of human life.

The type of scenario presented by $\operatorname{Re} C$ should serve to alert us to the dangers inherent in the $R e T$ approach - an approach which, in relying upon a minimal definition of capacity, has extended the principle of patient autonomy beyond its proper bounds. It would be much better for the courts, when faced with a patient who is refusing life-saving treatment, to revert to the older idea of 'sound mind' and to hold that, as a matter of law, an irrational choice in this context cannot be the product of a sound mind.

Marc Stauch, MA (Oxon), is a Solicitor, and a Lecturer in Law at Nottingham Law School, Nottingham Trent University.

\section{References}

(1) [1992] 4 All England reports: 649.

(2) [1992] 4 All England reports: $652 \mathrm{j}-653 \mathrm{~b}$.

(3) Schloendorff v Society of New York Hospital (1914) 105 North eastern reporter: 92.

(4) [1986] Appeal cases: 112.

(5) It in fact appears to stem from dicta in Templeman L's speech in Sidaway $v$ Board of Governors of the Bethlem and Maudsley Hospital [1985] Appeal Cases: 871,904 . It has since found support in Airedale NHS Trust $\mathrm{v}$ Bland [1993] 2 weekly law reports: $316,360,367, \& 393$.

(6) [1994] 1 Weekly law reports: 290.

(7) HMSO 1993, para 2.12.

(8) HMSO 1993, paras 2.14 and 2.15.

(9) See $\operatorname{Re} T$ [1992] 4 All England law reports: 649, 661; Airedale NHS v Bland, 2 weekly law reports: 352 and 362.

(10) See $\operatorname{Re} \mathcal{F}$ (a minor) (wardship: treatment) [1991] 1 family law reports: 366,381 .

(11) See, for example, $\operatorname{Re} W$ (a minor) [1992] 4 All England law reports: 627, per Lord Donaldson M R, at 637: 'I personally consider that religious or other beliefs which bar any medical treatment or treatment of particular kinds are irrational, but that does not make minors who hold those beliefs any the less "Gillick competent".'

(12) See $\operatorname{Re} J$ (a minor) (wardship: treatment) [1991] 1 family law reports: 366 . This view has been endorsed by the House of Lords in Airedale NHS Trust $v$ Bland.

(13) Wreen M J. Autonomy, religious values, and refusal of life-saving medical treatment. Fournal of medical ethics 1991; 17: 124-130.

(14) Kennedy I. In: Dyer C, ed. Doctors, patients and the law. Oxford: Blackwell Scientific Publications, 1992: 56.

(15) [1994] 1 weekly law reports: 290 . See also the article by C's Counsel, Gordon R and Barlow C. New law journal 1993; Dec 3: 1719-1720. 